John Carroll University

Carroll Collected

$5-2019$

\title{
Associations Between MMPI-2-RF Scale Scores and Institutional Violence Among Patients Detained Under Sexually Violent Predator Laws
}

Anthony M. Tarescavage

John Carroll University, atarescavage@jcu.edu

Allen Azizian

California State University, Fresno

Charles Broderick

Peter English

California State University, Fresno

Follow this and additional works at: https://collected.jcu.edu/fac_bib_2019

Part of the Psychology Commons

\section{Recommended Citation}

Tarescavage, Anthony M.; Azizian, Allen; Broderick, Charles; and English, Peter, "Associations Between MMPI-2-RF Scale Scores and Institutional Violence Among Patients Detained Under Sexually Violent Predator Laws" (2019). 2019 Faculty Bibliography. 11.

https://collected.jcu.edu/fac_bib_2019/11 


\title{
BRIEF REPORT
}

\section{Associations Between MMPI-2-RF Scale Scores and Institutional Violence Among Patients Detained Under Sexually Violent Predator Laws}

\author{
Anthony M. Tarescavage \\ John Carroll University \\ Charles Broderick \\ Department of State Hospitals, Sacramento, California
}

\author{
Allen Azizian \\ California State University, Fresno, and Department of State \\ Hospitals, Sacramento, California \\ Peter English \\ California State University, Fresno
}

\begin{abstract}
Sexually violent predator (SVP) laws allow the postprison civil commitment of sex offenders to a secure psychiatric hospital because of mental abnormality and posing a serious risk to public safety. Research on predictors of future institutional violence in this population is lacking because adequately sized samples are difficult to obtain. In the current study, we examined psychological predictors of future institutional violence in a sample of 171 psychiatrically hospitalized males detained or civilly committed under an SVP laws. Using the Minnesota Multiphasic-Personality Inventory-2-Restructured Form (Ben-Porath \& Tellegen, 2008/2011), we found that scales assessing thought dysfunction, emotional dysregulation, and externalizing behaviors were associated with future physical violence at the hospital. Relative risk ratio analyses indicated that SVPs producing elevations on these scales were at 1.5-2.5 times greater risk of future physical violence than those without elevations. Overall, the results suggest the Minnesota Multiphasic-Personality Inventory-2-Restructured Form is associated with future institutional violence among SVPs. Implications and limitations of these findings are discussed.
\end{abstract}

\section{Public Significance Statement}

This study identifies measures from a widely used psychological test (the Minnesota MultiphasicPersonality Inventory-2-Restructured Form) that can be used to predict institutional violence among individuals committed under sexually violent predator laws. Clinicians can use these findings to inform use of the Minnesota Multiphasic-Personality Inventory-2-Restructured Form among sexually violent predators.

Keywords: Minnesota Multiphasic-Personality Inventory-2-Restructured Form, sexually violent predator, violence risk assessment, institutional violence

Violence among some forensic patients admitted to state hospitals is a serious problem in the United States. Although significant research has been conducted on predictors of vio- lence among criminally and civilly committed psychiatric inpatients (Iozzino, Ferrari, Large, Nielssen, \& De Girolamo, 2015), research is lacking on some subpopulations. For exam- 
ple, forensic patients civilly committed under Sexually Violent Predator (SVP) Acts are hospitalized indefinitely until deemed no longer dangerous to the health and safety of others. Although the sexual recidivism rates in this population may be higher than non-SVP sex offenders, their risk for nonsexual institutional violence is mostly unknown. The lack of research in this area may reflect the small size of the institutionalized SVP population. Indeed, a 2005 survey found that only 3,022 individuals had been classified as SVPs across the entire United States (Washington State Institute for Public Policy, 2005). Moreover, only 10 states held more than 100 SVPs, illustrating the difficulty of obtaining samples of adequate size from this population. Most recent surveys report 4,534 individuals are held under SVP laws in the United States (Gookin, 2007).

The Minnesota Multiphasic-Personality Inventory-2-Restructured Form (MMPI-2-RF; Ben-Porath et al., 2008/2011) is a broadband psychodiagnostic instrument that holds promise for predicting violence among individuals detained as SVPs. The MMPI-2-RF is an updated version of the MMPI-2 (Butcher et al., 2001), which is commonly used in forensic settings (Archer, Buffington-Vollum, Stredny, \& Handel, 2006; Neal \& Grisso, 2014). The MMPI-2-RF was designed to improve on psychometric shortcomings of the MMPI-2, and it contains a scale structure consistent with modern models of psychopathology (Sellbom, Ben-Porath, \& Bagby, 2008). The MMPI-2-RF has nine validity scales designed to assess for invalid test-taking approaches, including random responding, acquiescent responding, overreporting, and underreporting. The MMPI-2-RF has 42 substantive scales assessing constructs from five domains: emotional/internalizing dysfunction, thought dysfunction, behavioral/externalizing dysfunction, interpersonal functioning, and somatic/cognitive complaints. These scales are organized into a series of hierarchical scale sets and include three higher-order scales, nine restructured clinical scales, 23 specific problems scales, and the Personality-Psychopathology-5 Scales.

Research supports the psychometrics of the MMPI-2-RF with sexual offenders. Tarescavage, Cappo, and Ben-Porath (2018) examined MMPI-2-RF scores in a sample of 304 males who were convicted of sexual offenses against children. They found adequate reliability estimates for scores from most scales, particularly those that were conceptually relevant to risk for future violence. The MMPI-2-RF was correlated with the STATIC-99 (Hanson \& Thornton, 1999) and Level of Service InventoryRevised (Andrews \& Bonta, 2000). Findings indicated that the MMPI-2-RF scales were associated with conceptually relevant violence-risk variables in expected ways, supporting their convergent validity.

There is a burgeoning research literature on use of the MMPI$2-\mathrm{RF}$ scales to predict future violence among forensic populations. For example, Grossi et al. (2015) examined associations between MMPI-2-RF scores and aggressive behaviors as coded on the Short-Term Assessment of Risk and Treatability (START) Outcomes Scale (Nicholls et al., 2007) among 219 forensic inpatients. They found that MMPI-2-RF measures of psychotic symptoms were the best predictors of violent behaviors along with the Juvenile Conduct Problems (JCP) scale. Tarescavage, Glassmire, and Burchett (2016) conducted a similar investigation of MMPI-2-RF predictors of future institutional violence in a sample of 303 forensic psychiatric inpatients. They found that the best predictors included MMPI-2-RF measures of emotional dysregulation and externalizing dysfunction.

\section{Current Study}

Past research has demonstrated the utility of the MMPI-2-RF in the prediction of future violence and has identified a need for focused research on violence prediction among SVPs. The purpose of the current study was to examine associations between MMPI2-RF scale scores and institutional violence among 171 psychiatrically hospitalized SVPs. To this end, we calculated partial pointbiserial correlations between MMPI-2-RF scale scores and a dichotomous future violence outcome variable while controlling for hospitalization time after testing. Based on the research reviewed earlier (Grossi et al., 2015; Tarescavage et al., 2016), we expected that scores from the following MMPI-2-RF scales would demonstrate significant, meaningful associations with future violence: THD, BXD, RC3, RC4, RC7, RC8, RC9, AXY, ANP, JCP, AGG, FML, IPP, AGGR-r, DISC-r, PSYC-r, and NEGE-r (Please see Tables 1 and 2 for scale names). The utility of other MMPI2-RF scale scores for this purpose was also explored. Finally, we examined the practical utility of the study findings by calculating relative risk ratios (RRRs). This analysis further quantified the practical implications of the findings by identifying the proportional increase in risk for institutional violence when MMPI-2-RF elevations occur.

\section{Method}

\section{Participants}

The study used an archival sample of 185 males who were detained or civilly committed pursuant to an SVP act to a maximum security state operated forensic hospital in the United States. We included individuals who produced valid MMPI-2-RF protocols according to standard interpretive guidelines (Cannot Say $<18$, VRIN- $r<80$, TRIN- $r<80$, F- $r<120$, Fp- $r<100$; Ben-Porath et al., 2008/2011). The final sample included 171 patients with an average age of 51.3 years $(S D=9.0)$. The sample was predominately White $(70.2 \%)$, followed by Black $(16.4 \%)$, Hispanic $(9.4 \%)$, and other $(4.0 \%)$. The average education level was 12.7 years $(S D=2.3)$. Excluded individuals did not significantly differ from the final sample on age, ethnicity, or years of

Table 1

MMPI-2-RF Validity Scale Descriptives $(N=171)$

\begin{tabular}{lcr}
\hline \multicolumn{1}{c}{ Variables } & $M$ & \multicolumn{1}{c}{$S D$} \\
\hline Variable response inconsistency (VRIN-r) & 49.6 & 10.3 \\
True response inconsistency (TRIN-r) & 50.0 & 9.0 \\
Infrequent responses (F-r) & 55.7 & 15.9 \\
Infrequent psychopathology responses (Fp-r) & 51.3 & 11.9 \\
Infrequent somatic responses (Fs) & 53.1 & 14.4 \\
Symptom validity (FBS-r) & 52.0 & 10.3 \\
Response bias scale (RBS) & 54.8 & 13.4 \\
Uncommon virtues (L-r) & 56.2 & 12.7 \\
Adjustment validity (K-r) & 57.0 & 11.3 \\
\hline
\end{tabular}

Note. MMPI-2-RF = Minnesota Multiphasic Personality Inventory-2Restrucutred Form. 
Table 2

MMPI-2-RF Substantive Scale Score Descriptives, Reliability, and Partial Point-Biserial Correlations With Future Institutional Violence (Controlling for Hospitalization Time After Test Administration) $(N=171)$

\begin{tabular}{|c|c|c|c|c|}
\hline \multirow[b]{2}{*}{ Scales } & \multirow{2}{*}{$\frac{\begin{array}{c}\text { Partial point- } \\
\text { biserial correlation }\end{array}}{\text { Future violence }}$} & \multicolumn{2}{|c|}{ Descriptives } & \multirow{2}{*}{$\frac{\text { Reliability }}{\text { Alpha }}$} \\
\hline & & $M$ & $S D$ & \\
\hline \multicolumn{5}{|l|}{ Higher-order scales } \\
\hline Emotional/internalizing dysfunction (EID) & .12 & 46.9 & 11.7 & .91 \\
\hline Thought dysfunction (THD) $)^{\mathrm{a}}$ & $.15^{*}$ & 50.1 & 11.1 & .75 \\
\hline Behavioral/externalizing dysfunction (BXD) ${ }^{\mathrm{a}}$ & .12 & 56.4 & 10.1 & .76 \\
\hline \multicolumn{5}{|l|}{ Restructured clinical scales } \\
\hline Demoralization (RCd) & .09 & 48.8 & 11.5 & .92 \\
\hline Somatic complaints ( $\mathrm{RC} 1)$ & $.13^{+}$ & 52.9 & 11.7 & .83 \\
\hline Low positive emotions (RC2) & $.18^{*}$ & 50.5 & 11.1 & .71 \\
\hline Cynicism $(\mathrm{RC} 3)^{\mathrm{a}}$ & $.15^{*}$ & 46.8 & 11.5 & .88 \\
\hline Antisocial behavior $(\mathrm{RC} 4)^{\mathrm{a}}$ & .05 & 61.8 & 11.1 & .79 \\
\hline Ideas of persecution (RC6) & $.14^{+}$ & 54.5 & 12.4 & .72 \\
\hline Dysfunctional negative emotions $(\mathrm{rc} 7)^{\mathrm{a}}$ & .12 & 44.8 & 10.8 & .88 \\
\hline Aberrant experiences $(\mathrm{RC} 8)^{\mathrm{a}}$ & $.15^{+}$ & 48.7 & 10.6 & .75 \\
\hline Hypomanic behavior (RC9) ${ }^{\mathrm{a}}$ & $.13^{+}$ & 44.8 & 9.7 & .80 \\
\hline \multicolumn{5}{|l|}{ Specific problems scales } \\
\hline Malaise (MLS) & $.16^{*}$ & 51.5 & 10.7 & 67 \\
\hline Gastrointestinal complaints (GIC) & .03 & 49.5 & 9.5 & .64 \\
\hline Head pain complaints (HPC) & $.17^{*}$ & 52.4 & 10.3 & .65 \\
\hline Neurological complaints (NUC) & .10 & 55.0 & 12.9 & .70 \\
\hline Cognitive complaints (COG) & .08 & 50.3 & 12.6 & .80 \\
\hline Suicidal/death ideation (SUI) & $.16^{*}$ & 48.7 & 10.4 & .68 \\
\hline Helplessness/hopelessness (HLP) & $.15^{+}$ & 47.8 & 9.9 & .50 \\
\hline Self-doubt (SFD) & .00 & 49.1 & 10.9 & .81 \\
\hline Inefficacy (NFC) & .04 & 48.3 & 9.4 & .72 \\
\hline Stress/worry (STW) & .06 & 44.7 & 9.5 & .66 \\
\hline Anxiety $(\mathrm{AXY})^{\mathrm{a}}$ & -.05 & 49.3 & 10.8 & .63 \\
\hline Anger proneness $(\mathrm{ANP})^{\mathrm{a}}$ & $.17^{*}$ & 47.1 & 10.4 & .80 \\
\hline Behavior-restricting fears (BRF) & .09 & 48.5 & 9.2 & .47 \\
\hline Multiple specific fears (MSF) & .05 & 47.6 & 7.7 & .64 \\
\hline Juvenile conduct problems (JCP) ${ }^{\mathrm{a}}$ & .07 & 60.4 & 13.1 & .73 \\
\hline Substance abuse (SUB) & -.02 & 53.2 & 8.9 & .48 \\
\hline Aggression $(\mathrm{AGG})^{\mathrm{a}}$ & $.19^{*}$ & 47.9 & 10.5 & .68 \\
\hline Activation (ACT) & .06 & 43.7 & 9.3 & .64 \\
\hline Family problems $(\text { FML })^{\mathrm{a}}$ & -.01 & 47.9 & 11.1 & .75 \\
\hline Interpersonal passivity (IPP) ${ }^{\mathrm{a}}$ & -.01 & 49.6 & 8.7 & .64 \\
\hline Social avoidance (SAV) & .09 & 51.0 & 10.0 & .76 \\
\hline Shyness (SHY) & .10 & 46.0 & 8.5 & .75 \\
\hline Disaffiliativeness (DSF) & $.15^{*}$ & 49.8 & 11.1 & .64 \\
\hline \multicolumn{5}{|l|}{ Personality-Psychopathology-5 scales } \\
\hline Aggressiveness (AGGR-r) ${ }^{\mathrm{a}}$ & .06 & 49.9 & 8.9 & .68 \\
\hline Psychoticism (PSYC-r) ${ }^{\mathrm{a}}$ & $.15^{+}$ & 48.7 & 10.6 & .74 \\
\hline Disconstraint (DISC-r) & .09 & 56.1 & 8.9 & .65 \\
\hline Negative emotionality/neuroticism (NEGE-r) ${ }^{\mathrm{a}}$ & .12 & 45.6 & 10.1 & .82 \\
\hline \multicolumn{5}{|l|}{ Introversion/low positive emotionality } \\
\hline (INTR-r) & .05 & 52.1 & 10.0 & .74 \\
\hline
\end{tabular}

Note. MMPI-2-RF = Minnesota Multiphasic Personality Inventory-2-Restructured Form.

${ }^{\mathrm{a}}$ Hypothesized scales.

${ }^{+} p<.10 .{ }^{*} p<.05$.

education (lowest $p=.11$ ). Patients had primary diagnoses of either pedophilic disorder $(66.5 \%)$ or other specified paraphilic disorder, nonconsent (33.5\%). Additionally, $29 \%$ of the sample had antisocial personality disorder.

\section{Measures}

MMPI-2-RF. As noted earlier, the MMPI-2-RF (BenPorath et al., 2008/2011) is a 338-item measure of personality psychopathology with 51 scales. Information about reliability, validity, and descriptive findings in a wide range of samples is reported in the MMPI-2-RF technical manual (Tellegen \& BenPorath, 2008/2011). In the current study, all patients were administered the MMPI-2, which was used to score the MMPI2-RF because all of the test's items are included in the MMPI-2 booklet. Past research supports the comparability of MMPI2-RF scores generated from the two booklets in a forensic 
setting (Tarescavage, Alosco, Ben-Porath, Wood, \& LunaJones, 2015).

Special incident reports. The outcome variable was derived from special incident reports (SIRs) completed by staff according to standard hospital policies, thereby allowing for a standardized method of assessing risk for future violence in the hospital. Hospital policy required SIRs to be completed any time one of the following two types of violent acts occurred in the facility: aggressive act to another patient-physical and aggressive act to staff-physical. Physical aggression was defined on the SIR form as hitting, pushing, kicking, or similar acts directed against another individual to cause potential or actual injury. We examined only SIRs that occurred after the date of MMPI-2 administration. Individuals who had a violent incident after testing were coded as 1 , whereas those who did not were coded as 0 . The base rate of institutional violence for this sample was $40.9 \%$. The average time of hospitalization after testing ranged from 5 days to 10.5 years $(M=5.4$ years, $S D=2.3$ years $)$.

\section{Procedures}

The study utilized a 9-year (2006-2016) retrospective review of the clinical records of individuals who were detained under probable cause $(n=83)$ or civilly committed $(n=102)$ to a state forensic hospital pursuant to the SVP Act. Participants had completed testing as part of routine assessment for treatment purposes. Diagnoses were made according to Diagnostic and Statistical Manual of Mental Disorders, fourth edition, text revision, or Diagnostic and Statistical Manual of Mental Disorders, fifth edition, criteria by at least two forensic evaluators and consensus from a multidisciplinary treatment team. The research was approved by the Committee for the Protection of Human Subjects, which serves as the institutional review board for California state agencies.

\section{Results}

\section{Descriptives}

We first compared means and standard deviations of the current sample with those produced by the MMPI-2-RF normative sample (which, by definition, has a mean of 50T and standard deviation of 10T). Consistent with traditional MMPI guidelines, we deemed a mean difference of $5 \mathrm{~T}$ or more as clinically meaningful (i.e., $S D=$ 0.5; Graham, 2012). In regard to the validity scales (see Table 1 for findings and scale names), we found that the current sample scored meaningfully higher than the normative sample on F-r, L-r, and K-r. The underreporting scales L-r and K-r demonstrated the largest differences among these scales. Regarding the substantive scales (see Table 2 for findings and scale names), the current sample scored meaningfully higher than the normative sample on BXD, RC4, NUC, JCP, and DISC-r. Among these scales, RC4 demonstrated the largest difference $(M=61.8, S D=11.1)$.

\section{Partial Point-Biserial Correlations With Future Violence}

We next calculated partial point-biserial correlations between the MMPI-2-RF substantive scale scores and the violence outcome variable (see Table 2). This analysis is used when correlating a continuous variable (such as MMPI-2-RF scores) and a dichotomous variable (such as our outcome variable). We controlled for hospitalization time after testing. Based on past research, we hypothesized significant associations for the following MMPI2-RF scale scores: THD, BXD, RC3, RC4, RC7, RC8, RC9, AXY, ANP, JCP, AGG, FML, IPP, AGGR-r, PSYC-r, DISC-r, and NEGE-r. Consistent with our hypotheses, we found significant associations between violence and THD, RC3, ANP, and AGG. The following scales also demonstrated significant associations: MLS, HPC, SUI, and DSF. Additionally, marginally significant associations were observed for RC1, RC6, RC8, RC9, HLP, and PSYC-r.

\section{Relative Risk Ratios}

To investigate the practical utility of our findings, we calculated RRRs using cutoffs of $65 \mathrm{~T}$ and $80 \mathrm{~T}$. RRRs are calculated by dividing the risk of a negative outcome for individuals who score at or above the cutoff by the risk of a negative outcome for individuals who score below the cutoff. We calculated $95 \%$ confidence intervals for the RRRs. Confidence intervals that overlap with the value 1.0 indicate nonsignificant findings. We calculated RRRs only for substantive scales that were hypothesized to demonstrate an association with violence or yielded a partial pointbiserial correlation value of $p<.05$ (as presented in Table 2). Only RRRs that yielded selection ratios (i.e., elevation rates) $\geq 2.0 \%$ were calculated to reduce the possibility of outliers affecting the results.

In Table 3 we present RRRs that met the just described selection criteria. To assist with interpretation, we next describe the RRR for THD and future violence (i.e., the first row of Table 3). The selection ratio indicates that $9.4 \%$ of the sample scored at or above a cutoff of $65 \mathrm{~T}$. The risk for violence is $68.8 \%$ if THD is $\geq 65 \mathrm{~T}$ and $38.1 \%$ if THD is $<65 \mathrm{~T}$. Dividing the risk if elevated by the risk if not elevated yields a RRR of 1.806. Because the $95 \%$ confidence interval for this analysis ranges from 1.23 to 2.66 , the finding is statistically significant (i.e., because the range does not overlap with 1.0). An RRR of 1.0 would indicate equal risk for future violence both below and above the cutoff. Overall, the RRR analyses demonstrated statistically significant and meaningful findings. For example, individuals with elevations of 65T on ANP were 1.7 times more likely to engage in violence, and those with elevations at $80 \mathrm{~T}$ on $\mathrm{RC} 2$ were 2.5 times more likely to have this outcome. Of note in this context, the base rate of violence in the current sample is approximately $40 \%$, meaning the maximum possible value of the RRR is approximately 2.5. That is, even if all individuals who elevated a scale were violent (risk if elevated $=$ $100 \%$ ), the nonelevated group would have a risk near the base rate (risk if not elevated $=40 \%$ ), so the maximum RRR is about 2.5 $(100 \% / 40 \%)$.

In post hoc analyses, we also examined the utility of combinations of scale elevations in predicting future violence (see Table 4). RRRs were calculated only for scale combinations involving ANP/ AGG and three other broad markers of psychopathology on the MMPI-2-RF identified as associated with violence in the current study (THD, BXD, and RC2). The ANP and AGG scales are narrow, specific measures of aggressive behaviors, whereas THD, $\mathrm{BXD}$, and RC2 are relatively broad measures of major forms of 
MMPI-2-RF AND VIOLENCE IN SVP

Table 3

RRRs for MMPI-2-RF Substantive Scales ${ }^{a}$ Predicting Institutional Violence $(N=171)$

\begin{tabular}{rlccccc}
\hline SR & Scale & Cutoff & Risk if elevated & Risk if not elevated & RRR & $95 \%$ CI \\
\hline $9.4 \%$ & THD & $65 \mathrm{~T}$ & $68.8 \%$ & $38.1 \%$ & $1.806^{*}$ & {$[1.23,2.66]$} \\
$22.2 \%$ & BXD & $65 \mathrm{~T}$ & $57.9 \%$ & $36.1 \%$ & $1.604^{*}$ & {$[1.13,2.28]$} \\
$13.5 \%$ & RC2 & $65 \mathrm{~T}$ & $60.9 \%$ & $37.8 \%$ & $1.609^{*}$ & {$[1.09,2.37]$} \\
$13.5 \%$ & RC3 & $65 \mathrm{~T}$ & $52.2 \%$ & $39.2 \%$ & 1.331 & {$[.86,2.07]$} \\
$39.2 \%$ & RC4 & $65 \mathrm{~T}$ & $49.3 \%$ & $35.6 \%$ & 1.384 & {$[.97,1.97]$} \\
$7.0 \%$ & RC7 & $65 \mathrm{~T}$ & $50.0 \%$ & $40.3 \%$ & 1.242 & {$[.68,2.26]$} \\
$9.4 \%$ & RC8 & $65 \mathrm{~T}$ & $50.0 \%$ & $40.0 \%$ & 1.250 & {$[.74,2.12]$} \\
$4.7 \%$ & RC9 & $65 \mathrm{~T}$ & $75.0 \%$ & $39.3 \%$ & $1.910^{*}$ & {$[1.23,2.98]$} \\
$12.3 \%$ & MLS & $65 \mathrm{~T}$ & $52.4 \%$ & $39.3 \%$ & 1.332 & {$[.85,2.10]$} \\
$15.2 \%$ & HPC & $65 \mathrm{~T}$ & $50.0 \%$ & $39.3 \%$ & 1.272 & {$[.82,1.96]$} \\
$12.3 \%$ & SUI & $65 \mathrm{~T}$ & $57.1 \%$ & $38.7 \%$ & 1.478 & {$[.97,2.25]$} \\
$9.9 \%$ & AXY & $65 \mathrm{~T}$ & $41.2 \%$ & $40.9 \%$ & 1.007 & {$[.55,1.83]$} \\
$9.9 \%$ & ANP & $65 \mathrm{~T}$ & $64.7 \%$ & $38.3 \%$ & $1.689^{*}$ & {$[1.13,2.53]$} \\
$31.6 \%$ & JCP & $65 \mathrm{~T}$ & $50.0 \%$ & $36.8 \%$ & 1.360 & {$[.95,1.94]$} \\
$8.8 \%$ & AGG & $65 \mathrm{~T}$ & $53.3 \%$ & $39.7 \%$ & 1.342 & {$[.80,2.24]$} \\
$6.4 \%$ & FML & $65 \mathrm{~T}$ & $54.5 \%$ & $40.0 \%$ & 1.364 & {$[.77,2.42]$} \\
$6.4 \%$ & IPP & $65 \mathrm{~T}$ & $72.7 \%$ & $38.8 \%$ & $1.877^{*}$ & {$[1.24,2.83]$} \\
$12.3 \%$ & DSF & $65 \mathrm{~T}$ & $57.1 \%$ & $38.7 \%$ & 1.478 & {$[.97,2.25]$} \\
$12.3 \%$ & AGGR-r & $65 \mathrm{~T}$ & $47.6 \%$ & $40.0 \%$ & 1.190 & {$[.73,1.94]$} \\
$9.4 \%$ & PSYC-r & $65 \mathrm{~T}$ & $62.5 \%$ & $38.7 \%$ & $1.615 \%$ & {$[1.05,2.48]$} \\
$20.5 \%$ & DISC-r & $65 \mathrm{~T}$ & $54.3 \%$ & $37.5 \%$ & 1.448 & {$[.99,2.1]$} \\
$7.0 \%$ & NEGE-r & $65 \mathrm{~T}$ & $50.0 \%$ & $40.3 \%$ & 1.242 & {$[.68,2.26]$} \\
$2.3 \%$ & RC2 & $80 \mathrm{~T}$ & $100.0 \%$ & $39.5 \%$ & $2.530^{*}$ & {$[2.10,3.05]$} \\
$6.4 \%$ & RC4 & $80 \mathrm{~T}$ & $36.4 \%$ & $41.3 \%$ & .882 & {$[.39,1.97]$} \\
$4.7 \%$ & AXY & $80 \mathrm{~T}$ & $50.0 \%$ & $40.5 \%$ & 1.235 & {$[.60,2.53]$} \\
$2.3 \%$ & ANP & $80 \mathrm{~T}$ & $100.0 \%$ & $39.5 \%$ & $2.530^{*}$ & {$[2.10,3.05]$} \\
$7.6 \%$ & JCP & $80 \mathrm{~T}$ & $38.5 \%$ & $41.1 \%$ & .935 & {$[.46,1.91]$} \\
$2.3 \%$ & DSF & $80 \mathrm{~T}$ & $75.0 \%$ & $40.1 \%$ & $1.869^{*}$ & {$[1.03,3.39]$} \\
\hline & & & & & \\
\hline
\end{tabular}

Note. $\mathrm{SR}=$ selection ratio; $\mathrm{CI}=$ confidence interval $\mathrm{BXD}=$ behavioral/externalizing dysfunction; $\mathrm{RC} 3=$ cynicism; RC4 = antisocial behavior; $\mathrm{RC} 7=$ dysfunctional negative emotions; $\mathrm{RC} 9$ = hypomanic activation; MLS = malaise; HPC = head pain complaints; SUI = suicidal ideation; AXY = anxiety; ANP = anger proneness; JCP = juvenile conduct problems; $\mathrm{AGG}=$ aggression; $\mathrm{FML}=$ family problems; IPP $=$ interpersonal passivity; DSF = disafiliativeness; AGGR = aggressiveness; DISC- $r=$ disconstraint; NEGE-r $=$ negative emotionality/neuroticism. Statistically significant findings are bolded.

${ }^{\text {a }}$ Relative Risk Ratios (RRRs) were calculated only for substantive scales that were hypothesized to demonstrate an association with violence or yielded a partial point-biserial correlation value of $p<.05$ (see Table 2 for correlates); base rate $=40.9 \%$

* Statistically significant $(p<.05)$.

psychopathology. We examined the risk of violence when both scales were elevated versus when both were not elevated. For this reason, individuals who elevated on only one scale in the combination were not included. This led to the exclusion of $10.0 \%(80 \mathrm{~T}$ on SUI/65T on EID) to $27.2 \%$ (65T on SUI/65T on BXD) of the overall sample, which limits the generalizability of the findings. Overall, these findings indicated that high scores on ANP combined with elevated scores on broad measures of externalizing

Table 4

Minnesota Multiphasic Personality Inventory-2-Restructured Form (MMPI-2-RF) Post Hoc Analysis: Relative Risk Ratios (RRRs) for Select Scale Combinations

\begin{tabular}{|c|c|c|c|c|c|c|c|c|}
\hline$N$ & BR & SR & Scale 1 (cutoff) & Scale 2 (cutoff) & Risk if elevated & Risk if not elevated & RRR & $95 \% \mathrm{CI}$ \\
\hline 152 & $38.2 \%$ & $4.6 \%$ & ANP (65T) & THD (65T) & $71.4 \%$ & $36.6 \%$ & $1.954^{*}$ & {$[1.17,3.27]$} \\
\hline 152 & $37.5 \%$ & $3.9 \%$ & AGG (65T) & THD (65T) & $50.0 \%$ & $37.0 \%$ & 1.352 & {$[.59,3.09]$} \\
\hline 138 & $38.4 \%$ & $8.0 \%$ & ANP (65T) & $\mathrm{BXD}(65 \mathrm{~T})$ & $72.7 \%$ & $35.4 \%$ & $2.053^{*}$ & {$[1.33,3.16]$} \\
\hline 135 & $37.0 \%$ & $2.2 \%$ & ANP (80T) & $\mathrm{BXD}(65 \mathrm{~T})$ & $100.0 \%$ & $35.6 \%$ & $2.809^{*}$ & {$[2.23,3.53]$} \\
\hline 142 & $38.0 \%$ & $8.5 \%$ & AGG (65T) & $\mathrm{BXD}(65 \mathrm{~T})$ & $58.3 \%$ & $36.2 \%$ & 1.613 & {$[.95,2.74]$} \\
\hline 145 & $35.2 \%$ & $4.8 \%$ & ANP (65T) & $\mathrm{RC} 2(65 \mathrm{~T})$ & $42.9 \%$ & $34.8 \%$ & 1.232 & {$[.51,2.99]$} \\
\hline
\end{tabular}

Note. $\mathrm{SR}=$ selection ratio $; \mathrm{BR}=$ base rate $\mathrm{CI}=$ confidence interval $\mathrm{ANP}=$ anger proneness $\mathrm{AGG}=$ aggression; $\mathrm{THD}=$ thought dysfunction; $\mathrm{BXD}=$ behavioral/externalizing dysfunction. Relative risk ratios were calculated only for scale combinations involving ANP/AGG and three other broad markers of psychopathology on the MMPI-2-RF identified as associated with violence (THD, BXD, and RC2); group scoring above both scale cutoffs is compared with group scoring below both scale cutoffs. Some scales and cutoffs were not included in the RRR analyses because they had selection ratios less than $2.0 \%$, which could lead to an increased chance for outliers affecting the results.

* Statistically significant $(p<.05)$. 
(BXD) and thought dysfunction (THD) yielded increased risk for violence.

\section{Discussion}

The purpose of this study was to determine whether MMPI2-RF scales are associated with institutional violence in a sample of SVPs, which is a population that is relatively small and underresearched. We first examined mean MMPI-2-RF scores and found that individuals in the sample produced above-average scores on measures of externalizing psychopathology as well as on measures of underreporting response styles. Correlational analyses indicated that MMPI-2-RF measures of thought dysfunction, emotional dysregulation, and externalizing psychopathology were associated with future violence. These findings were qualified by RRR analyses indicating that individuals were twice as likely to commit future violence when elevations on these scales occurred. Several aspects of these findings warrant further discussion.

Descriptive analyses indicated that the current sample presents with increased levels of underreporting. This finding is not altogether surprising because SVPs are involuntarily committed until they are deemed no longer a danger to the community and are not likely to engage in sexually violent criminal behavior. Thus, SVPs have an incentive to underreport psychological and behavioral problems. Despite increased levels of underreporting, the current sample did produce above-average scores on measures of externalizing psychopathology (particularly antisocial behavior). Nevertheless, these scores are likely to underestimate the sample's level of externalizing dysfunction because of underreporting (Forbey, Lee, Ben-Porath, Arbisi, \& Gartland, 2013). These findings underscore the benefits of using measures with well-established indicators of response style in assessments of SVPs, both in research and practice.

Correlational analyses between MMPI-2-RF scores and future violence generally converged with expectations based on past research. Grossi et al. (2015) found that MMPI-2-RF measures of thought dysfunction were the strongest predictors of violence in psychiatric patients, as measured by the START Outcomes Scale. In the current study, THD, RC8, and PSYC-r were either significant or marginally significant predictors of future violence. Tarescavage et al. (2016) found that MMPI-2-RF measures of cynicism, emotional dysregulation, and externalizing behaviors were associated with future violence among psychiatric inpatients. Similarly, in the current study, conceptually relevant significant/marginally significant predictors of future violence included RC3, RC9, ANP, and AGG.

Curiously, the current study found that several MMPI-2-RF indicators of externalizing psychopathology were not associated with future violence. To some extent, the lack of associations for these scales may reflect the impact of systematic error variation secondary to underreporting response styles. Indeed, as noted, the current sample had elevated levels of underreporting, and past research supports that externalizing measures are most impacted by this response style (Forbey et al., 2013). Contrary to expectations, RC2 was a significant predictor of future violence. This scale measures a lack of energy, anhedonia (inability to feel pleasure), and a lack of positive emotional experiences (Ben-Porath et al., 2008/ 2011). These characteristics, particularly lack of energy, would seem to make an individual less likely to engage in violent behavior.
However, it may be that depression in populations of male sexually violent predators manifests itself as irritable and/or aggressive behavior. Nevertheless, future research is needed to explore this finding.

The RRR analyses quantified the practical utility of the correlational findings. These findings indicated that patients who produced elevations on scales associated with future violence were at 1.5-2.5 times greater likelihood of engaging in violent behavior. The magnitude of these RRRs is particularly meaningful when considered in light of the base rate of future violence in this sample (40.9\%). For example, $100 \%$ of the sample that scored $\geq 80 \mathrm{~T}$ on the RC2 scale engaged in future violence, whereas patients scoring below that cutoff had a future violence rate of 39.5\%-consistent with the overall sample base rate. Accordingly, dividing the risk if elevated by the risk if not elevated yielded a RRR for this analysis (2.530) that was at maximum possible value. Of note, post hoc analyses indicated that individuals were at particular risk of future violence when producing elevated scores on anger proneness and thought dysfunction or behavioral/externalizing dysfunction. Indeed, the combination of an elevation of 80T on ANP and 65T on BXD yielded the largest RRR in the study.

The current study has several limitations that point to future directions in research. First, the dependent variable was heterogeneous as well as subjective because it was made up of multiple indicators of physical violence that were reported by hospital staff on institutionally mandated special incident forms. These study characteristics limit the specificity and reliability, respectively, of the findings. Along the same lines, because of the field-research nature of the sample, it was not possible to provide reliability information for the main outcome variable. In the absence of multiple raters, it is possible that the outcome variable was unreliable, which would result in attenuated associations and increased Type II error rates. Although we believe this limitation is outweighed by the need for investigations of violence in this relatively small population of SVPs, future research with potentially more reliable criteria is indicated. The second limitation is that the investigation utilized an archival sample of nonconsecutive inpatients. In general terms, this study characteristic is likely to decrease the variance in MMPI-2-RF scores, which will attenuate correlation coefficients. Therefore, it is possible that some of the scales demonstrating nonsignificant associations with the criterion in this study actually have meaningful associations with future violence. Future research with SVPs consecutively administered the MMPI-2-RF is needed. Finally, and also reflecting the limitations of an archival sample, the MMPI-2-RF findings and interpretations were available to hospital staff and may have been used to guide treatment and/or interventions to decrease violence risk. This aspect of the study could lead to decreased variance in the criterion, thereby attenuating associations.

Notwithstanding these limitations, the current study provides a much-needed examination of predictors of institutional violence among SVPs. Our results suggest that MMPI-2-RF measures of emotional dysregulation, thought dysfunction, and aggression can be used to predict future institutional violence in this important subpopulation of forensic inpatients.

\section{References}

Andrews, D. A., \& Bonta, J. (2000). The level of service inventory-revised. Toronto, Ontario, Canada: Multi-Health Systems. 
Archer, R. P., Buffington-Vollum, J. K., Stredny, R. V., \& Handel, R. W. (2006). A survey of psychological test use patterns among forensic psychologists. Journal of Personality Assessment, 87, 84-94. http://dx .doi.org/10.1207/s15327752jpa8701_07

Ben-Porath, Y. S., \& Tellegen, A. (2008/2011). MMPI-2-RF: Manual for administration, scoring and interpretation. Minneapolis: University of Minnesota Press.

Butcher, J., Graham, J. R., Ben-Porath, Y. S., Tellegen, A., Dahlstrom, G. W., \& Kaemmer, B. (2001). Minnesota Multiphasic Personality Inventory-2: Manual for administration, scoring, and interpretation. Minneapolis: University of Minnesota Press.

Forbey, J. D., Lee, T. T., Ben-Porath, Y. S., Arbisi, P. A., \& Gartland, D. (2013). Associations between MMPI-2-RF validity scale scores and extra-test measures of personality and psychopathology. Assessment, 20, 448-461. http://dx.doi.org/10.1177/1073191113478154

Gookin, K. (2007). Comparison of state laws authorizing involuntary commitment of Sexually Violent Predators: 2006 update, revised (Document No. 07-08-1101). Olympia: Washington Institute for Public Policy.

Graham, J. R. (2012). The MMPI-2: Assessing personality and psychopathology (5th ed.). New York, NY: Oxford University Press.

Grossi, L. M., Green, D., Belfi, B., McGrath, R. E., Griswold, H., \& Schreiber, J. (2015). Identifying aggression in forensic inpatients using the MMPI-2RF: An examination of MMPI-2-RF scale scores and estimated psychopathy indices. International Journal of Forensic Mental Health, 14, 231-244. http://dx.doi.org/10.1080/14999013.2015.1108943

Hanson, R. K., \& Thornton, D. (1999). Static 99: Improving actuarial risk assessments for sex offenders (Vol. 2). Ottawa, Ontario: Solicitor General Canada.

Iozzino, L., Ferrari, C., Large, M., Nielssen, O., \& de Girolamo, G. (2015). Prevalence and risk factors of violence by psychiatric acute inpatients: A systematic review and meta-analysis. PLOS ONE, 10, e0128536. http:// dx.doi.org/10.1371/journal.pone.0128536

Neal, T. M. S., \& Grisso, T. (2014). Assessment practices and expert judgment methods in forensic psychology and psychiatry: An interna- tional snapshot. Criminal Justice and Behavior, 41, 1406-1421. http:// dx.doi.org/10.1177/0093854814548449

Nicholls, T. L., Gagnon, N., Crocker, A. G., Brink, J., Desmarais, S., \& Webster, C. D. (2007). START Outcomes Scale (SOS). Vancouver, BC: Mental Health and Addiction Services.

Sellbom, M., Ben-Porath, Y. S., \& Bagby, R. M. (2008). On the hierarchical structure of mood and anxiety disorders: confirmatory evidence and elaboration of a model of temperament markers. Journal of Abnormal Psychology, 117, 576-590.

Tarescavage, A. M., Alosco, M. L., Ben-Porath, Y. S., Wood, A., \& Luna-Jones, L. (2015). Minnesota Multiphasic Personality Inventory-2Restructured Form (MMPI-2-RF) scores generated from the MMPI-2 and MMPI-2-RF test booklets: Internal structure comparability in a sample of criminal defendants. Assessment, 22, 188-197. http://dx.doi org/10.1177/1073191114537347

Tarescavage, A. M., Cappo, B. M., \& Ben-Porath, Y. S. (2018). Assessment of sex offenders with the Minnesota Multiphasic Personality/ Inventory-2-Restructured Form. Sexual Abuse, 30, 413-437. http://dx .doi.org/10.1177/1079063216667921

Tarescavage, A. M., Glassmire, D. M., \& Burchett, D. (2016). Introduction of a conceptual model for integrating the MMPI-2-RF into HCR-20V3 violence risk assessments and associations between the MMPI-2-RF and institutional violence. Law and Human Behavior, 40, 626.

Tellegen, A., \& Ben-Porath, Y. S. (2008/2011). Minnesota Mutliphasic Personality Inventory-2-Restructured Form: Technical manual. Minneapolis: University of Minnesota Press.

Washington State Institute for Public Policy. (2005). Involuntary commitment of sexually violent predators: Comparing state laws. Olympia, Washington: Author. Retrieved from http://www.wsipp.wa.gov/ReportFile/899/ Wsipp_Involuntary-Commitment-of-Sexually-Violent-Predators-Comparing-State-Laws_Full-Report.pdf 